\title{
Modeling of Rotary Kiln in Cement Industry
}

\author{
Hamid Reza Goshayeshi, Fariba Kerdar Poor \\ Department of Mechanical Engineering, Mashhad Branch, Islamic Azad University, Mashhad, Iran \\ Email: goshayshi@yahoo.com
}

Received 7 September 2015; accepted 26 January 2016; published 29 January 2016

Copyright (C) 2016 by authors and Scientific Research Publishing Inc.

This work is licensed under the Creative Commons Attribution International License (CC BY).

http://creativecommons.org/licenses/by/4.0/

c) (i) Open Access

\begin{abstract}
Cement production is a highly energy-intensive process, and the rotary kiln is the most important part of the process. Having a comprehensive model of the kiln in order to reduce manufacturing costs, better performance can be created. In this paper, the influence processes in a simulated cement rotary kiln and operating parameters on the output of the study were to develop and validate the systems using the same batch. The followings were examined: solid phase, gas and coating temperature change in a rotary kiln.
\end{abstract}

\section{Keywords}

\section{Rotary Kiln, Cement, Heat Loss, Energy}

\section{Introduction}

In today's world, powering along the supply of raw materials, cement production is the most important factor. Cement production process is extremely time-consuming [1] and the rotary kiln is the most important part of the process, which is considered as the heart of it. Rotary kiln due to its complex nature (physical and chemical reactions simultaneously) and various parameters affecting the quality of research on the dynamics of complex, is very necessary [2]. Ongoing maintenance and operation of the rotary kiln are vital. It is very expensive, because that would stop the kiln production. After having a comprehensive model of the process, we can create a better performance of the kiln, and the model can be used for operator training by experienced operators expert in the industry used [3], and eventually a reduced energy consumption in the cement industry.

\section{Description of Cement Rotary Kiln}

A simple system for cement rotary kiln is shown in Figure 1. Rotary kiln is basically a cylinder of length 50 $120 \mathrm{~m}$ (modern kilns) and 3.5 to 6.5 feet in diameter. 
During kiln mainly on how long it takes until the temperature of the raw material clinker temperature of about $1370^{\circ} \mathrm{C}$ is, it depends. The modern design of the plant, a cyclone preheater to increase the temperature of the solid input materials are used to shorten the length of the kiln.

Raw materials to the kiln consist of calcium carbonate $\left(\mathrm{CaCO}_{3}\right)$, silica $\left(\mathrm{SiO}_{2}\right)$, shale $\left(\mathrm{Al}_{2} \mathrm{O}_{3}\right)$ and iron oxide $\left(\mathrm{Fe}_{2} \mathrm{O}_{3}\right)$ feeds. These compounds are very fine powder and mixed with cement to form [4].

\section{Energy Balance}

For the balance of power in the rotary kiln, the average temperature of the walls was used in this model. The following equations for the gas, and solid walls, respectively [5] written.

According to the equation:

$$
Q=\dot{m}_{i} C_{p i} \Delta T_{i}
$$

where $\dot{m}_{i}$ ( $i$ mass flow rate in $\left.\mathrm{kg} / \mathrm{s}\right), C_{p i}\left(i\right.$ specific heat capacity in $\mathrm{kJ} /\left(\mathrm{kg} \cdot{ }^{\circ} \mathrm{C}\right)$ ), $\Delta T_{i}(i$ temperature change according to ${ }^{\circ} \mathrm{C}$ ), $Q$ (heat in $\mathrm{kJ}$ ) is, and $\dot{m}_{i}$ replaced by the following equation:

$$
\dot{m}_{i}=\rho_{i} v_{i} A_{i}
$$

That $\rho_{i}\left(i\right.$ density in $\left.\mathrm{kg} \cdot \mathrm{m}^{3}\right), v_{i}(i$ speed in $\mathrm{m} / \mathrm{s}), A_{i}\left(i\right.$ surface area in $\left.\mathrm{m}^{2}\right)$. Therefore the temperature in the gas phase transport equations are:

$$
A_{g} C_{p g} \rho_{g} v_{g} \frac{\partial T_{g}}{\partial z}=\beta_{1}\left(T_{w}-T_{g}\right)+\beta_{2}\left(T_{s}-T_{g}\right)+Q_{\text {comb }}
$$

where $T_{w}$ (wall temperature by ${ }^{\circ} \mathrm{C}$ ), $T_{g}$ (gas temperature in ${ }^{\circ} \mathrm{C}$ ), $T_{s}$ (solid temperature in ${ }^{\circ} \mathrm{C}$ ), $\beta_{1}$ (heat transfer coefficient between the wall and the gas in $\mathrm{W} /{ }^{\circ} \mathrm{C}$ ), $\beta_{2}$ (transfer coefficient between the solid and the gas temperature in $\mathrm{W} /{ }^{\circ} \mathrm{C}$ ), $Q_{\text {comb }}$ (combustion heat in $\mathrm{W}$ ), $v_{g}$ (gas velocity in $\mathrm{m} / \mathrm{s}$ ), $\rho_{g}$ (average gas density of $0.85 \mathrm{~kg} / \mathrm{m}^{3}$ ), $\partial T_{g} / \partial z$ (gas temperature changeover the elements in ${ }^{\circ} \mathrm{C} / \mathrm{m}$ ), $C_{p g}$ (gas specific heat capacity of $1173.8 \mathrm{~kJ} / \mathrm{kg} /{ }^{\circ} \mathrm{C}$ ) and $A_{g}$ (of gas per $\mathrm{m}^{2}$ ) and $v_{g}$ obtained from the following equations:

$$
v_{g}=\frac{\left(\dot{m}_{f}+\dot{m}_{a}\right)}{A_{g} \cdot \rho_{g}}
$$

That $\dot{m}_{f}$ (fuel mass flow rate) and $\dot{m}_{a}$ (air mass flow rate) is:

$$
A_{g}=\frac{r_{1}^{2}}{2}(p-\sin p)
$$

That $r_{1}$ (radius of the kiln according tom) and $p$ (surrounded by a solid angle $3 \pi / 2$ ) and the solid phase are:

$$
A_{s} C_{p s} \rho_{s} v_{s} \frac{\partial T_{s}}{\partial z}=\beta_{2}\left(T_{g}-T_{s}\right)+\beta_{3}\left(T_{w}-T_{s}\right)+A_{s} Q_{c}
$$

That $\beta_{3}$ (heat transfer coefficient between the wall and solid in terms of $\mathrm{W} /{ }^{\circ} \mathrm{C}$ ), $Q_{c}$ (heat of reaction in terms of $\mathrm{W}$ ), $v_{s}$ (solid velocity in $\mathrm{m} / \mathrm{s}$ ), $\rho_{s}$ (solid density of $890 \mathrm{~kg} / \mathrm{m}^{3}$ ), $\partial T_{s} / \partial z$ (solid temperature changes over the elements in ${ }^{\circ} \mathrm{C} / \mathrm{m}$ ), $C_{p s}$ (specific heat capacity of solid $1089.97 \mathrm{~kJ} / \mathrm{kg} /{ }^{\circ} \mathrm{C}$ ) is, $A_{s}$ (solid surface in $\mathrm{m}^{2}$ ) and $v_{s}$ calcu-

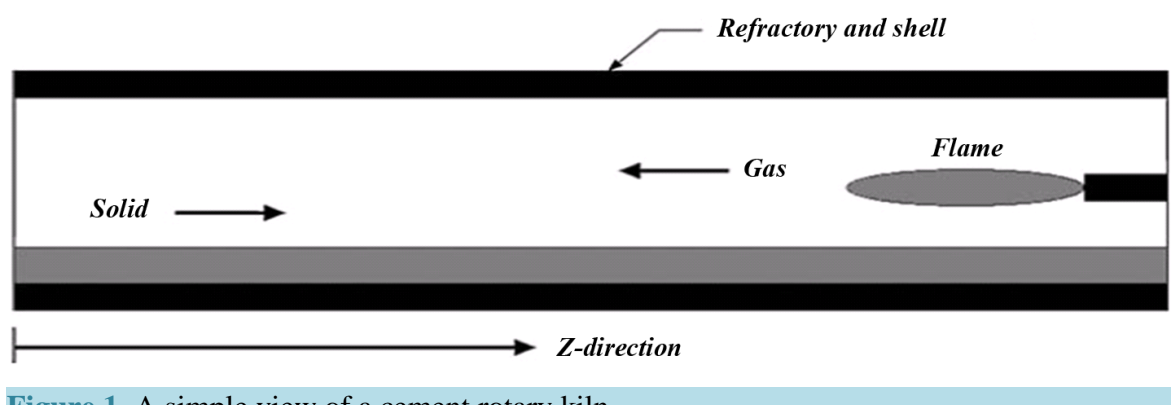

Figure 1. A simple view of a cement rotary kiln. 
lated from the following equations:

$$
\begin{gathered}
v_{s}=\frac{\dot{m}_{s}}{A_{s} \cdot \rho_{s}} \\
A_{s}=\frac{r_{1}^{2}}{2}(2 \pi-p+\sin p)
\end{gathered}
$$

Wall:

$$
\beta_{1}\left(T_{g}-T_{w}\right)+\beta_{3}\left(T_{s}-T_{w}\right)+\beta_{4}\left(T_{a}-T_{w}\right)=0
$$

That $\beta_{4}$ (heat transfer coefficient between the wall and the environment in terms of $\mathrm{W} /{ }^{\circ} \mathrm{C}$ ) and to calculate the heat of reaction is:

$$
Q_{c}=\frac{\rho_{s}}{\left(1+A_{i}+F_{i}+S_{i}\right)}\left[-\Delta H_{\xi} k_{1} \xi-\Delta H_{\omega} R_{\omega}-\Delta H_{\beta} R_{\beta} S(C)^{2}-\Delta H_{\alpha} k_{\alpha} C \beta\right]
$$

where $\omega$ (initial value water $/ \mathrm{CaO}$ ), $\xi$ (initial value $\mathrm{kg} \mathrm{CaCO}_{3} / \mathrm{kg} \mathrm{CaO}$ ), $\alpha$ (initial value $\mathrm{kg} \mathrm{C}_{3} \mathrm{~S} / \mathrm{kg} \mathrm{CaO}$ ), $\beta$ (quantity $\mathrm{kg} \mathrm{C}_{2} \mathrm{~S} / \mathrm{kg} \mathrm{CaO}$ ), $A_{i}$ (initial value $\mathrm{kg} \mathrm{Al}_{2} \mathrm{O}_{3} / \mathrm{kg} \mathrm{CaO}$ ), $F_{i}$ (initial value $\mathrm{kg} \mathrm{Fe}_{2} \mathrm{O}_{3} / \mathrm{kg} \mathrm{CaO}$ ), $S_{i}$ (initial value $\mathrm{kg}$ $\mathrm{SiO}_{2} / \mathrm{kg} \mathrm{CaO}$ ) and $C$ (the initial value of $\mathrm{CaO}$ ) is.

$$
\Delta H_{\xi}=2.966 \times 10^{6}(\mathrm{~J} / \mathrm{kg}), \Delta H_{\alpha}=25.59 \times 10^{3}(\mathrm{~J} / \mathrm{kg}), \Delta H_{\beta}=887.37 \times 10^{3}(\mathrm{~J} / \mathrm{kg}), \Delta H_{\omega}=2.256 \times 10^{6}(\mathrm{~J} / \mathrm{kg})
$$

And $A_{w}$ (wall surfaceinm ${ }^{2}$ ) of Equation (11) is calculated as:

$$
A_{w}=2 \pi\left(r_{2}^{2}-r_{1}^{2}\right)
$$

where $r_{2}$ (external beam kiln in $\mathrm{m}$ ) is, $\beta_{1}, \beta_{2}, \beta_{3}$ and $\beta_{4}$ linear function of temperature, and radiation heat transfer coefficient and geometry that can Equations (12) to (16) is calculated as:

$$
\begin{gathered}
\beta_{1}=1.7307 r_{2} p\left[f_{1}+1.73 \times 10^{-9}\left(1-h_{o}\right) \varepsilon_{g} \varepsilon_{w}\left(T_{g}^{2}+T_{w}^{2}\right)\left(T_{g}+T_{w}\right)\right] \\
\beta_{2}=3.4314 r_{1} \sin \left(\frac{p}{2}\right)\left[f_{2}+1.73 \times 10^{-9}\left(1-h_{o}\right) \varepsilon_{g} \varepsilon_{s}\left(T_{g}^{2}+T_{s}^{2}\right)\left(T_{g}+T_{s}\right)\right] \\
\beta_{3}=r_{1}(2 \pi-p)\left[f_{3}+1.73 \times 10^{-9} h \varepsilon_{w} \varepsilon_{s}\left(T_{s}^{2}+T_{w}^{2}\right)\left(T_{s}+T_{w}\right)\right]
\end{gathered}
$$

$h_{o}$ fraction of the radiation $0.0757, f_{1}$ (conductivity gas to the wall), $f_{2}$ (conductivity solid to gas), $f_{3}$ (conductivity wall of the gas), $\varepsilon_{w}=0.9, \varepsilon_{s}=0.8, \varepsilon_{g}=0.1$, respectively coefficient gas, solid wall and $h$ (radiation coefficient between solid and wall $\mathrm{W} / \mathrm{m}^{2} /{ }^{\circ} \mathrm{C}$ ) is calculated from the following equation:

$$
\begin{gathered}
h=1+\frac{2 h_{o} \sin \left(\frac{p}{2}\right)}{2 \pi-p} \\
\beta_{4}=2 \pi f_{4} r_{2}
\end{gathered}
$$

That $f_{4}$ (conductivity of the wall) and $f_{1}=f_{2}=f_{3}=f_{4}=22.71 \mathrm{~W} / \mathrm{m}^{2} /{ }^{\circ} \mathrm{C}$ is. To calculate the heat transfer coefficient between the wall and the environment (external air), Spang of Equation (16) is used. This is a perfect description of the heat transfer coefficients between the shell and the environment. Since $f_{4}$ the kiln was fixed, $\beta_{4}$ not sensitive to the conditions in the longitudinal direction. To increase the accuracy of the model, the heat transfer coefficient of the outer shell of the total displacement $h_{c s h \rightarrow a}$ and radiation $h_{\text {Rsh } \rightarrow a}$ was considered as follows:

$$
h_{c s h \rightarrow a}=\frac{0.11 k_{a} \operatorname{Pr}^{0.36}}{D}\left(0.5 R e_{w}^{2}+R e^{2}+G r\right)^{0.35}
$$


That Re (Reynolds number), Gr (Grashof number), $k_{a}$ (air conductivity), $\operatorname{Pr}$ (Prandtl number), $D$ (shell diameter in meters) is:

$$
h_{R s h \rightarrow a}=C^{\prime} \varepsilon_{s h} \sigma T_{s h}^{3}
$$

where $C$ in Equation (18) is obtained as follows:

$$
C^{\prime}=\left\{1+\frac{T_{a}}{T_{s h}}+\left(\frac{T_{a}}{T_{s h}}\right)^{2}+\left(\frac{T_{a}}{T_{s h}}\right)^{3}\right\}
$$

where $T_{a}$ (ambient temperature on ${ }^{\circ} \mathrm{C}$ ), $T_{\text {sh }}$ (shell temperatures in ${ }^{\circ} \mathrm{C}$ ) and $\varepsilon_{s h}=0.5$ (emission shell) and $\sigma=$ $5.6697 \times 10^{-8} \mathrm{~W} / \mathrm{m}^{2} \cdot{ }^{\circ} \mathrm{C}^{4}$. As to the equation (16) deduced $h_{c s h \rightarrow a}$ is temperature dependent. To $\mathrm{Pr}, \operatorname{Re}$ and $\mathrm{Gr}$ can be strongly influenced by environmental conditions. Therefore, to improve the model, first, the temperature of the kiln shell, the shell temperature scanner must be registered.

To calculate the film temperature $\left(T_{f}\right.$ according $\left.{ }^{\circ} \mathrm{C}\right)$ fluid inside the kiln elements are considered in the following equation can be used [6]:

$$
T_{f}=\frac{T_{s h}+T_{a}}{2}
$$

In each of the elements considered by the kiln shell surface temperature $T_{s h}$ in ${ }^{\circ} \mathrm{C}, T_{a}$ is the ambient temperature in ${ }^{\circ} \mathrm{C}$. So much $h_{c s h \rightarrow a}$ can be calculated at any point in the kiln. After calculating the temperature of the kiln is calculated film dimensionless groups. Heat transfer in the kiln body and Reynolds number Grash of What ratio are studied. If the Reynolds number is greater than the number Grashf $\left(R e_{D}^{2}>G r\right)$ forced displacement. Otherwise, the free movement of forced displacement in [2]:

$$
N u_{\text {forced }}=h_{\text {sh }} \frac{D}{k_{\infty}}=0.3+\frac{0.62 R e_{D}^{0.5} \operatorname{Pr}^{0.33}}{\left[1+\left(\frac{0.4}{P r}\right)^{0.66}\right]^{0.25}}\left[1+\left(\frac{R e_{D}}{28200}\right)^{a}\right]^{b}
$$

where $N u_{\text {forced }}$ (Nusselt forced displacement) and:

$$
\begin{gathered}
10^{2}<R e_{D}<10^{4} \rightarrow a=\frac{5}{8}, b=\frac{4}{5} \\
4 \times 10^{4}<R e_{D}<10^{7} \rightarrow a=\frac{1}{2}, b=1 \\
R e_{D}=\frac{\rho u d}{\mu}, G r_{D}=\frac{g \beta L^{3}\left(T_{\text {surf. }}-T_{a}\right)}{\vartheta^{2}}, \beta=\frac{1}{T}, \operatorname{Pr}=\frac{\mu C_{p}}{k_{a}}
\end{gathered}
$$

where $\mu$ (kinematic viscosity in terms of $\mathrm{kg} / \mathrm{m} \cdot \mathrm{s}$ ), $\rho$ (density in $\mathrm{kg} / \mathrm{m}^{3}$ ), $u$ (velocity in $\mathrm{m} / \mathrm{s}$ ), $d$ (diameter in $\mathrm{m}$ ), $g$ (acceleration due to gravity in $\mathrm{m} / \mathrm{s}^{2}$ times with 9.8 ), $T_{\text {surf }}$ (depending on the surface temperature ${ }^{\circ} \mathrm{C}$ ), $T_{a}$ (depending on the ambient temperature ${ }^{\circ} \mathrm{C}$ ), $L$ (characteristic length in $\mathrm{m}$ ), $\vartheta$ (dynamic viscosity in $\mathrm{m}^{2} / \mathrm{s}$ ), $k_{a}$ (air conductivity in $\mathrm{W} / \mathrm{m} \cdot{ }^{\circ} \mathrm{C}$ ), $\beta$ (coefficient of gas expansion in $1 /{ }^{\circ} \mathrm{C}$ ) [6] and on the free movement:

$$
N u_{\text {free }}=h_{\text {sh }} \frac{D}{k_{a}}=0.6+\frac{0.386 R a^{1.6}}{\left[1+\left(\frac{0.559}{P r}\right)^{\frac{9}{16}}\right]^{\frac{8}{27}}}
$$

where $N u_{\text {free }}$ (free convection Nusselt number) and Ra (Riley number) [7]:

$$
10^{-4}<R a<10^{12}, R a=P r G r_{D}
$$




\section{Flame Model}

Plug flow of cement rotary kiln flame model is used [8]. In this model, the flame is divided into $n$ cut to size. The thickness of each slice (step-size) mathematical equations solver that will be discussed later.

The number of sections is calculated as follows:

$$
n=\frac{F_{L}}{\text { Simulation step-size }}
$$

Flame length overall, $F_{L}$, the equation Beer is obtained:

$$
F_{L}=6 d_{0}\left(1+A F^{*}\right)\left(\frac{\rho_{e}}{\rho_{c p}}\right)^{0.5}\left(\frac{\rho_{e}}{\rho_{s e}}\right)^{0.5}
$$

The $A F^{*}$ (stoichiometric air-fuel ratio), $\rho_{e}$ (equivalent to gas density), $\rho_{c p}$ (density of combustion products), $\rho_{s e}$ (solid density published), $d_{0}$ (equivalent diameter of the burner) is. Gorog, cement kiln burner Coaxial type equipped [8]:

$$
\begin{gathered}
\rho_{e}=\frac{\dot{m}_{F}+\dot{m}_{p a}}{\frac{\dot{m}_{f}}{\rho_{F}}+\frac{\dot{m}_{p a}}{\rho_{p a}}} \\
d_{0}=\frac{\dot{m}_{F}+\dot{m}_{p a}}{\left[\left(G_{F}+G_{p a}\right) \pi \rho_{e}\right]^{0.5}} \\
A F^{*}=\frac{A F \dot{m}_{F}-\dot{m}_{p a}}{\dot{m}_{F}}
\end{gathered}
$$

The $\dot{m}_{f}$ (fuel mass flow rate in $\mathrm{kg} / \mathrm{s}$ ) and $\dot{m}_{s a}$ (secondary air mass flow rate in $\mathrm{kg} / \mathrm{s}$ ) can be recorded from the primary data cement kiln. The $\dot{m}_{p a}$ (primary air mass flow rate in $\mathrm{kg} / \mathrm{s}$ ) is calculated by knowing $\dot{m}_{s a}$ and $10 \%$ excess air to the burner, is calculated.

$G_{F}$ and also $G_{P a}$ in Equation (26) to the flow rate of fuel and primary air. Now $Q_{c o m b}$ in Equation (3) is calculated by the following expression:

$$
Q_{\text {comb }}=\frac{m_{F} \times \mathrm{LHV}+m_{p a} \times G_{p a} \times\left(T_{p a}-T_{r e f}\right)+m_{s a} \times G_{s a} \times\left(T_{s a}-T_{a}\right)}{\text { Simulation step-size }}
$$

where $T_{s a}$ (depending on the secondary air temperature ${ }^{\circ} \mathrm{C}$ ), LHV (lower heating value fuel in $\mathrm{J} / \mathrm{kg}$ ), $T_{p a}$ (primary air temperature in ${ }^{\circ} \mathrm{C}$ ), $T_{\text {ref }}$ (adjusted reference temperature ${ }^{\circ} \mathrm{C}$ ) is.

\section{Rotary Kiln Reaction Kinetic Rates}

Rates of chemical reactions rotary kiln using Arrhenius equation can be expressed as follows [9]:

$$
k_{i}=A_{i} \exp \left(\frac{-E_{i}}{R T_{s}}\right)
$$

The solid temperature $T_{s}$ by ${ }^{\circ} \mathrm{C}$, and $R=8.314 \mathrm{~J} / \mathrm{mol} \cdot{ }^{\circ} \mathrm{C}$ gas constant, $A_{i}(i$ based on the frequency factor $1 / \mathrm{h}$ ) and $E_{i}\left(i\right.$ activation energy in $\mathrm{J} / \mathrm{k} \mathrm{mol}$ ) and $k_{i}$ (Arrhenius constant reaction $i$ by $1 / \mathrm{h}$ ) is.

In which:

$$
i=\mathrm{CaO}, \mathrm{C}_{3} \mathrm{~S}, \mathrm{C}_{2} \mathrm{~S}, \mathrm{C}_{3} \mathrm{~A}, \mathrm{C}_{4} \mathrm{AF}, \mathrm{H}_{2} \mathrm{O}, \mathrm{CO}_{2}
$$

And by chemical reactions in cement rotary kiln, we have: 


$$
\begin{aligned}
& R_{\mathrm{H}_{2} \mathrm{O}}=\left\{\begin{array}{l}
-k_{\mathrm{H}_{2} \mathrm{O}} \frac{M_{\mathrm{H}_{2} \mathrm{O}}}{M_{\mathrm{CaO}}} \frac{M_{\mathrm{H}_{2} \mathrm{O}}}{M_{\mathrm{CaO}}} \leq 0.1 \\
-k_{\mathrm{H}_{2} \mathrm{O}} \frac{M_{\mathrm{H}_{2} \mathrm{O}}}{M_{\mathrm{CaO}}}>0.1
\end{array}\right. \\
& R_{\mathrm{CaCO}_{3}}=-\frac{M_{\mathrm{CaCO}_{3}}}{M_{\mathrm{CaO}}} \cdot k_{\mathrm{CaO}} \cdot C_{\mathrm{CaCO}_{3}} \\
& R_{\mathrm{C}_{3} \mathrm{~S}}=-\frac{M_{\mathrm{C}_{3} \mathrm{~S}}}{M_{\mathrm{CaO}}} \cdot k_{\mathrm{C}_{3} \mathrm{~S}} \cdot C_{\mathrm{CaO}_{3}} \cdot C_{\mathrm{C}_{2} \mathrm{~S}} \\
& R_{\mathrm{C}_{2} \mathrm{~S}}=-\frac{M_{\mathrm{C}_{2} \mathrm{~S}}}{2 M_{\mathrm{CaO}}} \cdot k_{\mathrm{C}_{2} \mathrm{~S}} \cdot C_{\mathrm{CaO}_{3}}^{2} \cdot C_{\mathrm{SiO}_{2}}-\frac{M_{\mathrm{C}_{2} \mathrm{~S}}}{M_{\mathrm{CaO}}} \cdot k_{\mathrm{C}_{3} \mathrm{~S}} \cdot C_{\mathrm{CaO}} \cdot C_{\mathrm{C}_{2} \mathrm{~S}} \\
& R_{\mathrm{C}_{3} \mathrm{~A}}=-\frac{M_{\mathrm{C}_{3} \mathrm{~A}}}{3 M_{\mathrm{CaO}}} \cdot k_{\mathrm{C}_{3} \mathrm{~A}} \cdot C_{\mathrm{CaCO}_{3}}^{3} \cdot C_{\mathrm{Al}_{2} \mathrm{O}_{3}} \\
& R_{\mathrm{C}_{4} \mathrm{AF}}=-\frac{M_{\mathrm{C}_{4} \mathrm{AF}}}{4 M_{\mathrm{CaO}}} \cdot k_{\mathrm{C}_{4} \mathrm{AF}} \cdot C_{\mathrm{CaO}_{3}}^{4} \cdot C_{\mathrm{Al}_{2} \mathrm{O}_{3}} \cdot C_{\mathrm{Fe}_{2} \mathrm{O}_{3}} \\
& R_{\mathrm{CaO}}=k_{\mathrm{CaO}} \cdot C_{\mathrm{CaCO}_{3}}-k_{\mathrm{C}_{3} \mathrm{~S}} \cdot C_{\mathrm{CaO}} \cdot C_{\mathrm{SiO}_{2}}-k_{\mathrm{C}_{2} \mathrm{~S}} \cdot C_{\mathrm{CaO}}^{2} \cdot C_{\mathrm{SiO}_{2}} \\
& -k_{\mathrm{C}_{3} \mathrm{~A}} \cdot C_{\mathrm{CaO}}^{3} \cdot C_{\mathrm{Al}_{2} \mathrm{O}_{3}}-k_{\mathrm{C}_{4} \mathrm{AF}} \cdot C_{\mathrm{CaO}}^{4} \cdot C_{\mathrm{Al}_{2} \mathrm{O}_{3}} \cdot C_{\mathrm{Fe}_{2} \mathrm{O}_{3}} \\
& R_{\mathrm{C}_{3} \mathrm{~S}}=-\frac{M_{\mathrm{SiO}_{2}}}{2 M_{\mathrm{CaO}}} \cdot k_{\mathrm{C}_{2} \mathrm{~S}} \cdot C_{\mathrm{CaO}_{3}}^{2} \cdot C_{\mathrm{SiO}_{2}} \\
& R_{\mathrm{F}_{2} \mathrm{O}_{3}}=-\frac{M_{\mathrm{C}_{4} \mathrm{AF}}}{4 M_{\mathrm{CaO}}} \cdot k_{\mathrm{C}_{4} \mathrm{AF}} \cdot C_{\mathrm{CaO}_{3}}^{4} \cdot C_{\mathrm{Al}_{2} \mathrm{O}_{3}} \cdot C_{\mathrm{Fe}_{2} \mathrm{O}_{3}} \\
& R_{\mathrm{CO}_{2}}=\frac{A_{s}}{A_{g}} \cdot \frac{\rho_{s}}{\rho_{g}} \cdot \frac{M_{\mathrm{CO}_{2}}}{M_{\mathrm{CaO}}} \cdot k_{\mathrm{CaO}} \cdot C_{\mathrm{CaO}_{3}}
\end{aligned}
$$

In these expressions $M_{i}\left(i\right.$ molecular mass in $\mathrm{kg} / \mathrm{m}^{3}$ ) and $R_{i}$ (kinetic rates $\left.i\right), C_{i}($ level $i)$ is.

\section{Mass Balance}

Mass imbalances, Equations (30) and (31) for 10 solid compound involved in the reactions occurring in cement kilns and other gas $\left(\mathrm{CO}_{2}\right)$ is written:

$$
\begin{array}{r}
R_{i}=\vartheta_{s} \frac{\partial C_{i}}{\partial z} \\
R_{j}=\vartheta_{g} \frac{\partial C_{j}}{\partial z}
\end{array}
$$

with: $i$ : $\mathrm{H}_{2} \mathrm{O}, \mathrm{CaCO}_{3}, \mathrm{SiO}_{2}, \mathrm{Al}_{2} \mathrm{O}_{3}, \mathrm{Fe}_{2} \mathrm{O}_{3}, \mathrm{CaO}, \mathrm{C}_{3} \mathrm{~S}, \mathrm{C}_{2} \mathrm{~S}, \mathrm{C}_{3} \mathrm{~A}, \mathrm{C}_{4} \mathrm{AF}$

and $j: \mathrm{CO}_{2}$.

$R_{i}$ (kinetic rates of the solid phase) and $R_{j}$ (gas phase kinetic rates) are presented in the previous section. Kinetic parameters are presented in the following Table 1.

\section{Modeling Assumptions}

These assumptions are as follows: 
Table 1. Parameters of reaction kinetics of cement rotary kiln.

\begin{tabular}{ccc}
\hline Reaction Rate & $A_{i}(1 / \mathrm{h})$ & $E_{i}(\mathrm{~J} / \mathrm{kmol})$ \\
\hline$k_{\mathrm{H}_{2} \mathrm{O}}$ & $1.94 \times 10^{4}$ & $42.08 \times 10^{6}$ \\
$k_{\mathrm{CaO}}$ & $4.55 \times 10^{31}$ & $805.8 \times 10^{6}$ \\
$k_{\mathrm{C}_{3} \mathrm{~S}}$ & $1.33 \times 10^{5}$ & $256.19 \times 10^{6}$ \\
$k_{\mathrm{C}_{2} \mathrm{~S}}$ & $4.11 \times 10^{5}$ & $193.31 \times 10^{6}$ \\
$k_{\mathrm{C}_{4} \mathrm{AF}}$ & $8.33 \times 10^{8}$ & $185.16 \times 10^{6}$ \\
$k_{\mathrm{C}_{3} \mathrm{~A}}$ & $8.33 \times 10^{6}$ & $194.10 \times 10^{6}$ \\
\hline
\end{tabular}

- Internal and external diameter of the kiln is assumed.

- The specific and reaction heat were independent of temperature and they were constant along the axial direction.

- Conduction in gases and solids in the axial direction of the wall was ignored.

- Displacement and diffusion coefficients are independent of temperature and location.

- Height and speed of the solids in the kiln section is assumed.

- solid material conveyed by the exhaust gas flow is not included in the model

- Arrhenius reaction rate specified by law.

- Average amount of coating conductivity $0.74 \mathrm{~W} / \mathrm{m}^{2} /{ }^{\circ} \mathrm{C}$ was considered.

- The conductivity of the refractory could be estimated by Equation (32) which was correlated from the experimental data, given by the refractory manufacturer for the magnetite-fried brick type is:

$$
k_{\text {reft }}=3195.5 \times T_{\text {reft }}^{(-0.9122)}
$$

- Conductivity of the metallic shell $45 \mathrm{~W} / \mathrm{m}^{2} /{ }^{\circ} \mathrm{C}$ is considered close to the alloy carbon steel.

- Since conductivity changes during the refractory lining is not possible, the starting amount was fixed. This assumption can be a source of grave error in the prediction model.

- The numbers of points scanned shell temperature kiln for a full rotation every 40 elements. At any point in the calculation of the axial position of an average value of all points in between.

\section{Cement Rotary Kiln Studied}

Length, diameter and outdoor cement kiln 70, respectively, 4.1 and 4.5 meters. Average thickness of $15 \mathrm{~cm}$ refractory magnetite, which can be considered to be uniform throughout the cooking area. Tilt cylinder to facilitate axial displacement of the solid bed, moving toward the discharge end in a state where the hot gases circulating in the opposite direction, was $4 \%$.

\section{Shell Temperature Scanner}

In Figure 2, the temperature measured by the scanner shell is provided. As can be downloaded from the possibility of severe changes in temperature measurement scale, there is a scanner. The reason for this phenomenon is the thickness of the coating. Since the coating thickness of 10 to 15 inches of cooking area is ideal for protection from fire in all areas [10]. To keep the coating thickness, shell temperature should be between $190^{\circ} \mathrm{C}$ and $220^{\circ} \mathrm{C}$. Temperature below a solid barrier to the movement of the kiln and the refractory layer is higher than a disadvantage.

\section{Simulation}

Mass and energy equations are integrated with a set of differential equations and algebraic models are flame by software MATLAB R2014a (ver. 8.3) is solved. Equations for the particular type of cooking area Hlknndh ODE15S are used. After solving the model, the wall temperature profile to the application submitted by Hlknndh ODE is solved. To solve the model equations, ODE during kiln divided into 70 elements. The size of each element of the program was considered a meter. The generated two-dimensional matrix, the temperature of the gas 


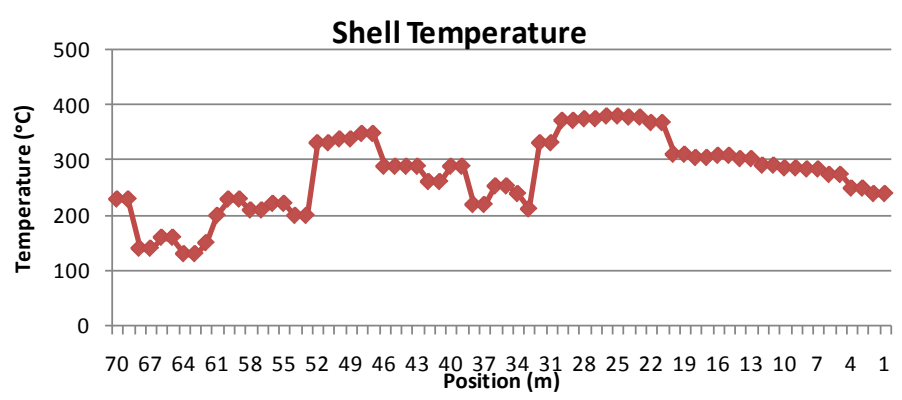

Figure 2. The temperature in the kiln shell scanner studied.

phase, solid coating in the oven during the show. Resistance between the wall and the surface layer is shown in Figure 3.

\section{Calculate the Energy Loss}

Heat flow in cylindrical coordinates (without heat) as follows [9]:

$$
\frac{\partial^{2} T}{\partial r^{2}}+\frac{1}{r} \frac{\partial T}{\partial r}+\frac{1}{r^{2}} \frac{\partial^{2} T}{\partial \phi^{2}}+\frac{\partial^{2} T}{\partial Z^{2}}=\frac{1}{\alpha} \frac{\partial T}{\partial \tau}
$$

For one-dimensional mode with the following assumptions, Equation (33) can be simplified:

$$
\frac{\partial^{2} T}{\partial r^{2}}+\frac{1}{r} \frac{\partial T}{\partial r}=0
$$

\section{Assumptions}

1) Steady-state heat transfer through the layers of the wall of the kiln (Steady-State) was considered.

2) The heat conductivity in the $z$ direction was ignored.

Thus, according to Figure 3, the following boundary conditions must be defined.

Coating layer: at $r=r_{w}, T=T_{w}$, \& at $r=r_{c}, T=T_{c}$

Refractory layer: at $r=r_{c}, T=T_{c}$, \& at $r=r_{b}, T=T_{b}$

Shel layer: at $r=r_{b}, T=T_{b}$, \& at $r=r_{\text {sh }}, T=T_{\text {sh }}$.

Therefore, the above equation with boundary conditions (34), the following equation is obtained:

$$
\begin{gathered}
Q_{\text {pass }}=\frac{2 \pi \Delta Z k_{c}\left(T_{w}-T_{c}\right)}{\ln \left(\frac{r_{c}}{r_{w}}\right)} \\
Q_{\text {pass }}=\frac{2 \pi \Delta Z k_{b}\left(T_{c}-T_{b}\right)}{\ln \left(\frac{r_{b}}{r_{c}}\right)} \\
Q_{\text {pass }}=\frac{2 \pi \Delta Z k_{s h}\left(T_{b}-T_{s h}\right)}{\ln \left(\frac{r_{s h}}{r_{b}}\right)} \\
Q_{\text {pass }}=2 \pi \Delta Z r_{s h} h_{s h \rightarrow a}\left(T_{s h}-T_{a}\right)
\end{gathered}
$$

At each stage $(\Delta Z)$, in the inner wall of the kiln temperature $\left(T_{w}\right)$ to find. Equations (1) to (28) are solved simultaneously in the program. Then, using Equations (38), (37) and (36), $Q_{\text {pass }}, T_{b}, T_{c}$, respectively, can be calculated. The simulation code, both inside the kiln wall temperature $\left(T_{w}\right)$ and the temperature of the kiln shell $\left(T_{s h}\right)$ as a two-dimensional matrix in terms of the length of the kiln is considered. We can conclude that the thermal 

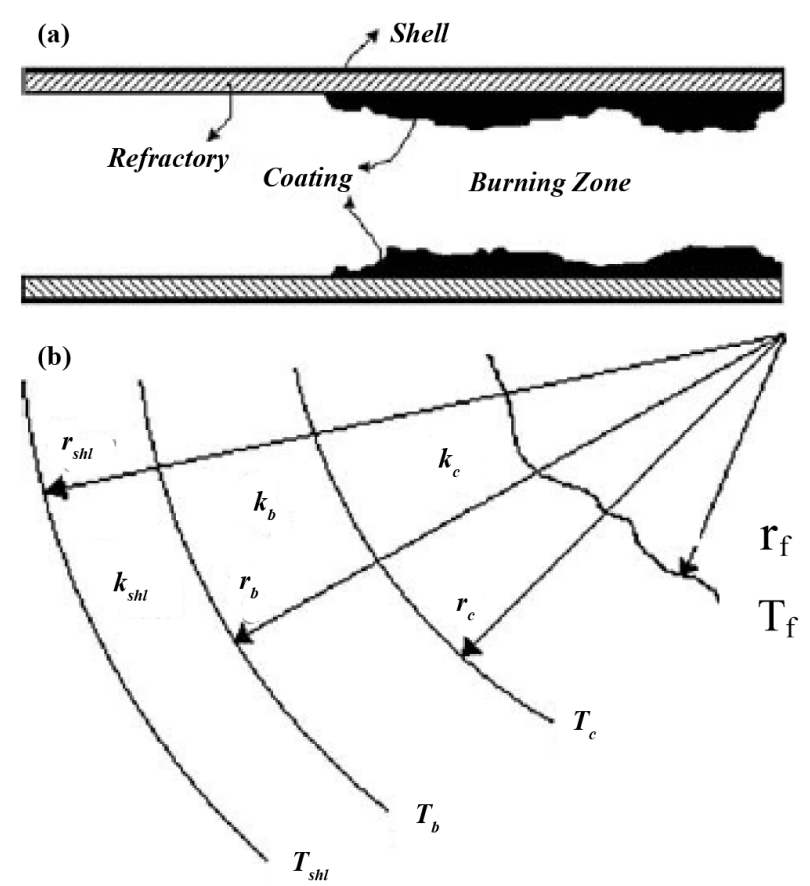

Figure 3. (a) Layers of walls in cement rotary kiln firing; (b) Resist layers.

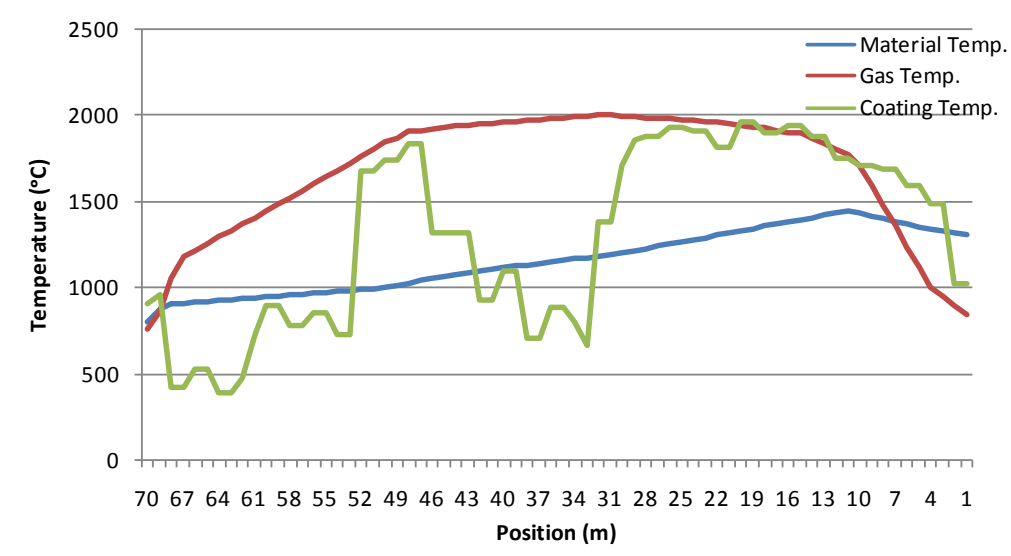

Figure 4. The temperature changes of the gas phase, the phase of the study materials and coating over $70 \mathrm{~m}$ rotary kiln.

resistance Equation (35) to (38) can be used to adapt the matrix elements, developed. Therefore, the heat loss from the body of the kiln is calculated (see Table 2).

\section{Results and Validate}

Now using equations results in mind, we can change the temperature of the solid phases, gas and coating in a rotary kiln were investigated (Figure 4). With the inlet and outlet temperature of the gas and solid modeling results with experimental results, we can infer that the model has good functionality.

Also according to the model equations, we can obtain the amount of waste in the rotary kiln (Figure 5).

\section{Discussion and Conclusions}

Since the temperature changes of the gas phase, solid coating of cement kilns was essential; therefore, an integrated model was developed in the cement kiln. First, a mathematical model of steady state (Steady-State) to estimate the inner wall surface of the rotary kiln temperature profiles was formulated. Then, by calculating the 


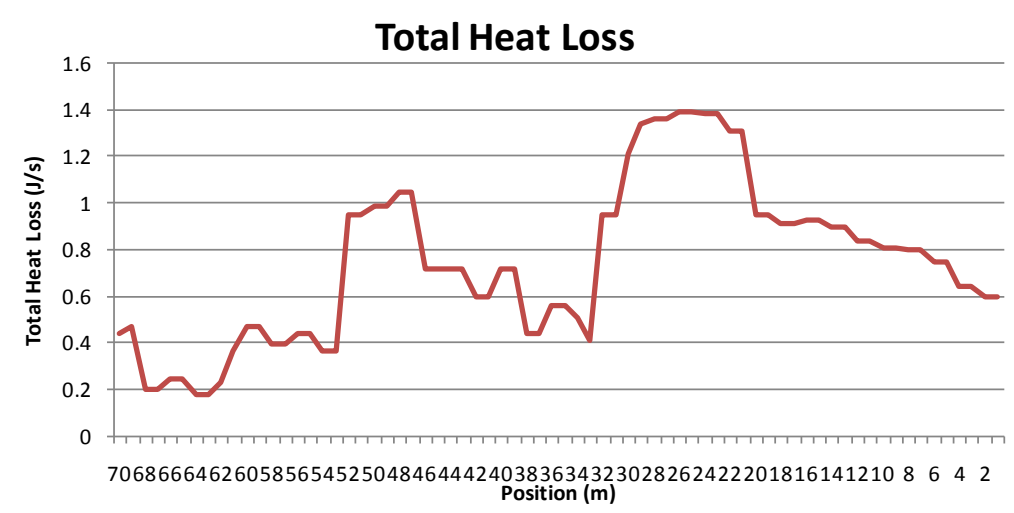

Figure 5. The total amount of waste in the body of the 70-meter rotary kiln studied.

Table 2. Rotary kiln operating conditions studied.

Ambient air temperature $\left({ }^{\circ} \mathrm{C}\right)$

Air velocity (m/s)

Secondary air inlet temperature $\left({ }^{\circ} \mathrm{C}\right)$

Secondary air flow rate $\left(\mathrm{m}^{3} / \mathrm{h}\right)$

Gas flow rate $\left(\mathrm{m}^{3} / \mathrm{h}\right)$

Feed rate (ton/h)

Kiln rotation speed (rpm)
20
5
1000
44,856
5479
205
2.8

temperature profile in the kiln and temperature profiles measured by the outside, the heat dissipation of body heat transfer resistance in the adjacent layers of the cylinder was estimated by the model. A comparison of model and data was collected from an industrial kiln, confirming that the feature is good for heat dissipation body temperature changes and the different phases. In addition, it is concluded that the heat loss from the body in the rotary kiln sintering temperature is greater than the thickness of the coating layer of the coating material, which does not create a problem.

\section{Acknowledgments}

Hereby, Mr. Doctor Yavari at Ghadir engineering companies in preparing this article appreciate their assistance and I appreciate it.

\section{References}

[1] Kerdarpour, F., Sufi, T., Goshayeshi, H.R. and Mir Sanjari, A. (2012) Investigation of Energy Waste in the Cement Industry and Solutions to Optimize Energy Consumption. International Journal of Petroleum and Energy, No. 86, 52.

[2] Boateng, A.A. (2011) Rotary Kiln. Shakeri, M.R. and Oghabi, M., Eds., Volume 1, Sharif University, Tehran,

[3] Noshirvani, G.R., Shirvani, M., Nourzadeh, H.R. and Saddiqi, S. (2010) Calculate and Estimate the Thickness of the Coating of Cement Rotary Kiln. Fourth Conference Condition Monitoring and Diagnostics of Machines, Sharif University, Tehran, 1388.

[4] Bouge, R.H. (1955) The Chemistry of Portland Cement. 2nd Edition, Reinhold, New York.

[5] Spang, H.A. (1972) A Dynamic Model of Cement Kiln. Automatic, 8, 309-323. http://dx.doi.org/10.1016/0005-1098(72)90050-7

[6] www.fa.wikibooks.org/wiki.

[7] Heidari, M. and Farhaniyeh, B. (2006) The Study of How to Determine the Depth of the Bed Material in the Rotary Kiln, Using Inverse Analysis. Journal of Research and Noble, No. 37, 118-107.

[8] Gorog, J.P., Adams, T.N. and Brimacombe, J.K. (2003) Heat Transfer from Flames in a Rotary Kiln. Metallurgical and 
Materials Transactions B-Process Metallurgy and Materials Processing Science, 14, 411-424. http://dx.doi.org/10.1007/bf02654360

[9] Sadighi, S., Shirvani, M. and Arshad, A. (2011) Rotary Cement Kiln Coating Estimator. The Canadian Journal of Chemical Engineering, 89, 116-125. http://dx.doi.org/10.1002/cjce.20365

[10] Bokaian, M. (1994) Cement Refractories and Building Materials. Handbook of Engineering, Vol. 2, 2nd Persian Edition, Training Department of Abyek Cement Industrial Complex, Iran. 